Bulletin d'Histoire Contemporaine de I'Espagne

$50 \mid 2016$

Les intellectuels en Espagne, de la dictature à la démocratie (1939-1986)

\title{
Rafael Calvo Serer. Un intelectual católico conservador
}

Rafael Calvo Serer. Un intellectuel catholique conservateur

Rafael Calvo Serer. A conservative catholic intellectual

\section{Sara Prades}

\section{OpenEdition}

\section{Journals}

Edición electrónica

URL: http://journals.openedition.org/bhce/545

DOI: $10.4000 /$ bhce. 545

ISSN: 1968-3723

Editor

Presses Universitaires de Provence

\section{Edición impresa}

Fecha de publicación: 1 diciembre 2016

Paginación: 85-98

ISSN: 0987-4135

\section{Referencia electrónica}

Sara Prades, « Rafael Calvo Serer. Un intelectual católico conservador », Bulletin d'Histoire

Contemporaine de l'Espagne [En línea], 50 | 2016, Publicado el 09 octubre 2018, consultado el 10

diciembre 2020. URL : http://journals.openedition.org/bhce/545 ; DOI : https://doi.org/10.4000/bhce. 545 


\section{La formación de un intelectual nacionalcatólico}

$\mathrm{R}$ afael Calvo Serer nació en Valencia el 6 de octubre de 1916 en la familia formada por Teresa Serer y José Ma Calvo, cofundador del sindicato Confederación de Obreros Católicos de Levante, por lo que conoció desde su infancia el ambiente político valenciano. Después de obtener el Premio Extraordinario de Bachillerato en el Instituto Luis Vives, comenzó en 1933 la licenciatura en Filosofía y Letras en la Universidad de Valencia ${ }^{1}$. Entre otros, recibió clases de Francisco Alcayde, quien influyó notablemente en la configuración de su pensamiento ${ }^{2}$. Durante la carrera fue becario del Colegio Mayor Beato Juan de Ribera de Burjassot, cuyo objetivo era proveer a los estudiantes universitarios que allí vivían de una educación que les impulsara a vivir su trabajo como servicio a la sociedad desde los valores del catolicismo. Como reconoció Calvo Serer en alguna ocasión, en el colegio se respiraba un ambiente tradicionalista evidenciado, por ejemplo, en las obras de que se nutría su biblioteca 3 .

Los colegiales, que eran entre quince y veinte cada curso escolar, recibían alojamiento y formación intelectual o espiritual pero, a cambio, se comprometían a obtener buenas calificaciones y a seguir las normas del colegio ${ }^{4}$. Allí Calvo residió junto a Federico Suárez Verdeguer, que estudiaba Filosofia y Letras un curso por detrás de él, o Alfredo Sánchez Bella, que era de su misma promoción. También fueron colegiales José Corts Grau, Juan José López Ibor, Pedro Laín Entralgo, Diego Sevilla Andrés, José Ombuena o Villar Palasí .

El Director del colegio, Antonio Rodilla, que al mismo tiempo era rector del Seminario Mayor de Valencia, canónigo de la catedral y vicario general de la diócesis, influyó

1 Siempre fue un excelente estudiante, como se observa en su expediente académico. Archivo Histórico de la Universitat de València (AHUV): Expediente Académico: 1221/23.

2 Onésimo Diaz Hernández, Rafael Calvo Serer y el grupo Arbor, Valencia, Universitat de València, 2008, p. 24. El autor expone que Antonio Fontán subrayó en una entrevista la influencia de las clases de este profesor monárquico y valencianista en Calvo Serer.

3 En una entrevista realizada en 1975 a la pregunta de cómo era la biblioteca del colegio Calvo contestó: «Muy escogida. Estaban todos los reaccionarios: Vázquez de Mella, Menéndez Pelayo, Donoso Cortés, Balmes... Ortega y Unamuno no estaban», en José Martí GómEz y Josep RamonedA, Calvo Serer: el exilio y el reino, Barcelona, Laia, 1976, p. 40.

4 En una carta de Pedro Pérez a Calvo Serer del 4 de octubre de 1943 se comentan algunos aspectos de la cotidianeidad del colegio como que se celebraba misa diaria, ejercicios espirituales, se impartian ciclos de conferencias o clases de inglés y alemán. Archivo General de la Universidad de Navarra (AGUN), Archivo Rafael Calvo Serer (RCS): 1/27/595.

5 AGUN, RCS: 1/27/212. Censo de Antiguos Alumnos del Colegio Mayor del Beato Juan de Ribera de Burjassot. 
notablemente en el joven Calvo, al interesarlo por la política y ponerlo en contacto con el Opus Dei. Su huella se percibe muy pronto, dado que Calvo comenzó su carrera política en la Universidad, al demostrar desde sus primeros años como estudiante un verdadero interés por la vida asociativa. De hecho, en 1935 fue nombrado presidente regional de la Confederación de Estudiantes Católicos, al tiempo que ostentaba el cargo de vicepresidente de la Juventud de Acción Católica de Valencia ${ }^{6}$. Debido a su cargo, hubo de realizar un breve pero decisivo viaje a Madrid durante las vacaciones escolares de marzo de 1936, en que había de contactar con otros representantes de los estudiantes católicos, con los falangistas del Sindicato Estudiantil Universitario y con los tradicionalistas de la Asociación Escolar Tradicionalista ${ }^{7}$.

Como vicepresidente de la Juventud Católica de Valencia, se entrevistó con destacados miembros de la Asociación Católica Nacional de Propagandistas como Ángel Herrera y Fernando Martín-Sánchez ${ }^{8}$. Al mismo tiempo, Calvo aprovechó su estancia en Madrid para conocer las instalaciones y a los principales impulsores de Acción Española como Eugenio Vegas Latapié, Ramiro de Maeztu o Jorge Vigón ${ }^{9}$. El joven universitario leía a menudo esta revista a la que estaba suscrito el Colegio Mayor de Burjassot e incluso, unos días antes de viajar a Madrid, había enviado al secretario de la misma una carta en que le exponía su admiración: «[...] Desengañado, después de estar mucho tiempo bajo la influencias de ideas, aunque santas "demasiado" extranjeras, encuentro en su Revista un contenido español y católico que en cuanto de mi dependa procuraré extender»» ${ }^{10}$.

Como se observa, en su juventud Calvo Serer estaba relacionado con las dos corrientes del catolicismo español. Desde principios del siglo XX, pero especialmente desde la década de los treinta, los católicos españoles se encontraban alineados en dos posiciones que han sido calificadas por distintos autores como "posibilistas e integristas»" estaban los miembros de la Asociación Católica Nacional de Propagandistas, fundada por el jesuita Ángel de Ayala y presidida por Ángel Herrera hasta 1935, que pretendía influir en la sociedad a través de una minoría de hombres bien preparados para el apostolado y la propaganda católica ${ }^{12}$. Habían sido un gran apoyo para la dictadura de Primo de Rivera y participaron en la II República con el partido Acción Popular, mediante el cual tenían la intención de afianzar la fe católica en la sociedad ${ }^{13}$. Esto fue posible gracias al impulso que dio quien fue su presidente hasta 1953, Fernando Martín-Sánchez.

Del otro lado estaban los nacionalcatólicos integristas, agrupados en torno a Acción Española. Políticos monárquicos, nobles, intelectuales, burgueses o clérigos que

6 Esplandiá, «Perfil humano de Rafael Calvo Serer», Punta Europa, 101, (1964), p. 114-126, p. 116.

7 Onésimo Diaz Hernández, op. cit., p. 23.

8 Mercedes Montero, Historia de la ACN de P. La construcción del Estado confesional (1936-1945), Pamplona, Eunsa, 1993, p. 34.

9 Eugenio Vegas Latapié, La frustración en la Victoria. Memorias políticas 1938-1942, Madrid, Actas, 1995, p. 107. El autor comenta que Calvo era el encargado de la subscripción del colegio de Burjassot a Acción Española.

10 Archivo personal de Eugenio Vegas Latapié (EVL), consultado en la Universidad de Navarra: 76/5/43. Carta de Calvo Serer a Vegas Latapié del 9 de marzo de 1936.

11 Pedro Carlos Gonzalez Cuevas, El pensamiento político de la derecha española del siglo XX. De la crisis de la Restauración al Estado de partidos (1898-2000), Madrid, Tecnos, 2005; Santos Juliá, Historias de las dos Españas, Madrid, Taurus, 2004, p. 282; Feliciano Montero, «Las derechas y el catolicismo español: del integrismo al socialcristianismo", Historia y Politica, 18 (2007), p. 101-128.

12 Antonio Fontán, Los católicos en la Universidad española actual, Madrid, Rialp, 1981, p. 40-50.

13 José Ramón Montero, La CEDA. El catolicismo social y politico en la II República, Madrid, Ediciones de la Revista de Trabajo, 1977. 
consideraban que el elemento católico era consubstancial a lo español e intentaban actualizar el pensamiento contrarrevolucionario europeo, distinguiendo entre el liberalismo político y el económico ${ }^{14}$. En 1933, desde posiciones muy próximas a Acción Española, surgió el partido monárquico Renovación Española, que nunca dejó de conspirar contra la República, aunque con resultados electorales exiguos ${ }^{15}$.

Además, en la breve estancia de Calvo Serer en Madrid, siguió las recomendaciones de Antonio Rodilla y fue a conocer a un viejo amigo suyo, el sacerdote José $\mathrm{M}^{a}$ Escrivá de Balaguer, que dirigía una residencia de estudiantes en dicha ciudad. La academia DYA impartía docencia en materias de Derecho y Arquitectura, pero también era una residencia de formación cristiana donde vivían algunos de los estudiantes que cursaban asignaturas allí. Escrivá de Balaguer había decidido extender este modelo de residencia fuera de Madrid, siendo Valencia la ciudad elegida. Para ello, necesitaba la ayuda de algún joven que buscase un piso próximo a la universidad, tarea que encargó a Calvo Serer. Quedó en verse con él en Valencia al mes siguiente, momento en que el universitario decidió su incorporación al Opus Dei ${ }^{16}$.

Al comenzar la guerra en julio de 1936, la familia de Calvo Serer huyó a La Marina, después de que su primo, presidente valenciano de la Asociación de Estudiantes Tradicionalistas, fuese fusilado. A pesar de haberse refugiado en Alcalalí, el joven Calvo fue igualmente movilizado por parte del ejército republicano en el verano de 1937. Pasó por los frentes de Madrid, Aragón y Valencia, donde ejerció de miliciano de la cultura por su condición de universitario. Después de pasar algunos meses en el hospital por problemas pulmonares, fue declarado inútil para el servicio de armas y eximido de luchar en el frente. Esa fue la razón por la que pudo volver a casa en septiembre de 1938 a esperar el fin de la guerra $^{17}$.

Mediado el conflicto, retomó sus estudios y residencia en el Colegio de Burjassot, donde fue nombrado decano en 1940. Allí mismo, Escrivá de Balaguer dirigió en junio de 1939 sus primeros retiros espirituales para universitarios, recuperando su intención de extender su influencia fuera de Madrid ${ }^{18}$. Después de establecer algunos contactos, los universitarios valencianos del Opus Dei encontraron un pequeño piso de alquiler para compartir hasta julio de 1940, cuando lo abandonaron para trasladarse a una gran casona en la que instalaron su primera residencia. Colaboraron en su establecimiento, entre otros, Calvo Serer, Ismael Sánchez Bella, Ángel López-Amo y Suárez Verdeguer.

Ese curso académico Calvo Serer ocupó una plaza de ayudante de clases prácticas y, más tarde, de auxiliar adscrito a la cátedra de Historia Universal Moderna y Contemporánea ${ }^{19}$. Una vez hubo obtenido el grado de licenciado, comenzó a preparar su tesis doctoral bajo la dirección de Santiago Montero Díaz ${ }^{20}$, al tiempo que impartía clases de Historia de

14 Alfonso Boттı, Cielo y dinero. El nacional-catolicismo en España (1881-1975), Madrid, Alianza, 1992, p. $141-142$.

15 Julio Gil Pecharroman, Conservadores subversivos. La derecha autoritaria alfonsina, 1913-1936, Madrid, EUDEMA, 1994.

16 Juan Luis Corbin, La Valencia que conoció San Josemaria Escrivá, Valencia, Carena, 2002, p. 17-18. En aquel momento el Opus Dei tenía diecinueve miembros, véase John F. Coverdale, La Fundación del Opus Dei, Barcelona, Ariel, 2002, p. 159-160.

17 Esplandián, op. cit., p. 118.

18 Juan Luis Corbin, op. cit., p. 52.

19 AHUV: Expediente Personal: $1349 / 7$.

20 Santiago Montero Diaz habia ganado la cátedra de Historia de la Edad Media Universal de la Universidad de Murcia en febrero de 1936. Durante la Guerra Civil habia apoyado al bando sublevado, participando 
España en la Facultad de Filosofia y Letras de la Universidad de Valencia como profesor encargado de la cátedra vacante ${ }^{21}$. Ese verano defendió su tesis doctoral sobre «Menéndez Pelayo y la decadencia española» en la Universidad Central, ante un tribunal formado por los profesores Pedro Sáinz Rodríguez, Francisco Cantera Burgos, Joaquín Entrambasaguas y Luis Morales Oliver.

Su estudio sobre Menéndez Pelayo revelaba al joven doctor como uno de los nuevos valores del nacionalcatolicismo español, que concluía que la decadencia de la patria podría no haber existido, razón por la que entendía que la recuperación del rumbo histórico previo al declive solo se conseguiría mediante la aniquilación de la antinación. El nacionalcatolicismo, enraizado en el siglo XIX y nacido como reacción a la revolución, las ideas ilustradas y el fin del Antiguo Régimen, tuvo a uno de sus primeros referentes en Juan Donoso Cortés y su Ensayo sobre el catolicismo, el liberalismo y el socialismo, que teorizaba acerca de que España era el baluarte del catolicismo en Europa y que la Iglesia era incompatible con la revolución. Loaba también la obra de Jaime Balmes, que defendía la superioridad del catolicismo ${ }^{22}$.

El teórico más importante del nacionalcatolicismo fue Menéndez Pelayo, que destacó la cristianización del Renacimiento gracias a Luís Vives, encarnación del genio español, del que habían de quedar excluidos los heterodoxos. En Historia de los heterodoxos españoles analizó las distintas posiciones no ortodoxas surgidas en el seno del catolicismo español para destacar la consubstancialidad de lo español y lo católico ${ }^{23}$. Igualmente, para esta cultura política fueron de capital importancia las ideas de Ramiro de Maeztu sobre el sentido reverencial del dinero y su intento de aplicar las teorías de Max Weber al catolicismo, asumiendo, de este modo los presupuestos económicos de la modernidad sin aceptar, en ningún caso, los políticos ${ }^{24}$. Así, Calvo Serer se insertaba en esta cultura política que tenía una peculiar visión de España, del Estado y de la sociedad e intentaba elaborar una vía que hiciese compatible el desarrollo capitalista español con la tradición.

\section{Un catedrático de veinticinco años}

Durante el curso 1940-1941 Calvo Serer estuvo pensionado por el Ayuntamiento de Valencia para desarrollar investigaciones en el ámbito de la Historia de las Instituciones, circunstancia que posibilitó su acercamiento a Alfonso García-Gallo, director del Seminario de Historia de las Instituciones subvencionado por el Consistorio ${ }^{25}$. En ese momento publicó su primer artículo en el Anuario de Historia del Derecho Español, dependiente del Instituto

en actos de propaganda, por lo que una vez terminó la contienda fue reintegrado a su función activa sin imposición de sanción, tras el correspondiente expediente de depuración. Obtuvo el trasladó a la Universidad de Madrid, donde se encargó durante muchos anos de la cátedra de Historia de la Filosofía Antigua de la Facultad de Filosofia y Letras. Desde alli dirigió cuarenta y cuatro tesis doctorales, entre cuyos autores estaban Rafael Calvo Serer, Federico Suárez Verdeguer, José Maria Sánchez de Muniaín Gil, Carlos Corona Baratech, Constantino Láscaris-Comneno Micolaw, Juan Torres Fontes, Elias Martínez Ruiz, Emilio Lledó Iñigo y Manuel Espadas Burgos. Véase www. filosofia.org.

21 AHUV: Expediente Personal: $1349 / 7$.

22 Alfonso BotTI, «Algo más sobre nacionalcatolicismo», en J. de la Cueva Merino y J. A. Lopez VILlaverde (coords.), Clericalismo y asociacionismo católico en España de la Restauración a la transición: un siglo entre el palio y el consiliario, Cuenca, Ed. Univ.Castilla la Mancha, 2005, p. 196.

23 Ismael SAZ, España contra España, Madrid, Marcial Pons, 2003, p. 53.

24 José Luís Villacañas, Ramiro de Maeztu y el ideal de la burguesía en España, Madrid, Espasa Calpe, 2000 , p. 174 y ss.

25 AHUV: Expediente Personal: 1349/7. 
Nacional de Estudios Jurídicos y dirigido por García-Gallo desde 1932, en que analizó un tema legislativo que mantenía una directa relación con los estudios del catedrático de Historia del Derecho ${ }^{26}$. Como colofón, en julio de ese año fue galardonado con el premio que otorgaba el Ayuntamiento de Valencia con motivo de los Juegos Florales por su trabajo «Valencia Ciudad de la Artesanía»"

Al inicio del siguiente curso universitario, Calvo se trasladó a Madrid para preparar las oposiciones a cátedra, aprovechando ese invierno para reforzar sus relaciones con personalidades del ámbito monárquico. Gracias a sus contactos publicó sus primeros artículos nacionalcatólicos, en que reflexionaba sobre la tradición como instrumento para regenerar espiritualmente a España y Europa ${ }^{28}$.

Aprobó las oposiciones en mayo de 1942 y se convirtió en el nuevo catedrático de Historia Universal Moderna y Contemporánea de la Facultad de Filosofía y Letras de la Universidad de Valencia ${ }^{29}$. La Universidad de posguerra proporcionó a los jóvenes licenciados extraordinarias oportunidades laborales, al quedar vacantes muchas cátedras debido al exilio, la depuración o la muerte. El caso de la Universidad de Valencia fue especialmente llamativo, dado que aquí fueron sancionados trece catedráticos y siete auxiliares, otros fueron jubilados y unos más trasladados y, como episodio más grave, se fusiló al rector en mayo de 1941, de igual manera que ocurrió en Oviedo y Granada ${ }^{30}$.

En esta coyuntura, Calvo se hizo con una cátedra, aunque no estaba dispuesto a conformarse con el más alto escalón de la carrera universitaria y, desde el primer momento, apuntó más lejos. Comenzó lo que iba a ser una constante en su vida: las reiteradas excedencias, el descuido de la docencia universitaria y las múltiples faltas a clase. Por eso se puede concluir que Calvo Serer utilizó su cargo en la Universidad como una plataforma de promoción pública que lo iba a empujar a más altas posiciones políticas.

De hecho, solo un año después de conseguir la cátedra, en el verano de 1943, pidió una excedencia para llevar a cabo una estancia de seis meses en Suiza, a cargo de la Junta de Relaciones Culturales, que dependía del Ministerio de Asuntos Exteriores. En Zurich pretendía estudiar alemán y Filosofía e Historia de la Edad Moderna europea, pero lo más destacable de su estancia es que fue recibido por Eugenio Vegas Latapié e introducido en el círculo del conde de Barcelona. Durante aquellos meses, Vegas adoctrinó al joven catedrático en el ideario de Acción Española ${ }^{31}$. Su discurso era similar al de los nacionalistas reaccionarios europeos, que rechazaban el liberalismo político proponiendo, de alguna forma, una vuelta a las instituciones del Antiguo Régimen, asentadas sobre la Monarquía y la Iglesia ${ }^{32}$. Quien había sido secretario de Acción Española le mostró que existían iniciativas parecidas en Francia, Italia o Portugal ${ }^{33}$.

26 Rafael Calvo Serer, «Libro de los Juisyos de la Corte del Rey», Amuario de Historia del Derecho Español, tomo XIII, (1941), p. 284-308.

27 AHUV: Expediente Personal: 1349/7.

28 Rafael CALvo SERER, «El sentido español del Renacimiento», Escorial, tomo VII, 1942, p. 197-307; «En torno al concepto de Renacimiento», Escorial, tomo VII, (1942), p. 355-387; «Sobre los origenes de lo moderno", Escorial, tomo VIII, 1942, p. 435-441.

29 AHUV: Expediente Personal: 1349/7.

30 Mariano Peset y M$M^{a}$ Fernanda MAnCeBo, «Exili i depuracions» en Mariano Peset (coord.), Història de la Universitat de València, Valencia, Universitat de València, 2000, p. 249-257.

31 Rafael Calvo Serer, Mis enfrentamientos con el poder, Barcelona, Plaza y Janés, 1978, p. 18.

32 Ismael $\mathrm{SAZ}$, «Mucho más que crisis políticas: el agotamiento de dos proyectos enfrentados», Ayer, $\mathrm{n}^{\circ}$ 68,2007 , p. $137-163$, p. 141.

33 Véase al respecto Alfonso Botrt, «Algo más..., op. cit., p. $195-212$ y p. 206 y ss. 
Un tiempo después, Calvo Serer volvió de Suiza para presentarse a unas nuevas oposiciones, en este caso a la cátedra de Historia General de la Cultura de la Facultad de Filosofía y Letras de Madrid. Al suspender, decidió marchar otros seis meses al país alpino, a pesar de la dificultad de transitar por Europa debido a la Segunda Guerra Mundial, donde estrechó relaciones con Don Juan de Borbón y entabló amistad con el clérigo catalán Carles Cardó ${ }^{34}$. La estancia de investigación acabó en marzo de 1945, momento en que Calvo Serer volvió a Madrid con la misión de exponer a los monárquicos el Manifiesto de Lausanne, para lo cual se entrevistó durante la primavera de aquel año con nobles, empresarios, intelectuales y militares.

En dicho escrito el conde de Barcelona rechazaba la práctica política llevada a cabo por el régimen y su concepción totalitaria del Estado, al tiempo que abogaba por el establecimiento de una Monarquía tradicional en que se respetasen los derechos fundamentales de la persona, como único sistema político capaz de ofrecer una paz duradera a los españoles. Proponía y reclamaba otro elemento del ideario de Acción Española, el reconocimiento de la diversidad regional, por eso se puede considerar que este manifiesto es fruto del momento en que los miembros de este grupo político-cultural estuvieron más cerca que nunca de imponer sus ideas en el círculo del conde de Barcelona ${ }^{35}$. Don Juan concluía su escrito pidiendo a sus allegados la no colaboración con el régimen por «contribuir a prolongar una situación que está en trance de llevar al país a una irreparable catástrofe $)^{36}$. Como era de esperar, el Manifiesto no fue bien recibido por Franco, que advirtió en un telegrama al heredero al trono que este texto suponía una vuelta a los valores que había defendido la II República:
El Jefe del Estado me encarga comunique a V. E. Conde de Barcelona que manifiesto cuyo texto me ha anticipado, atenta contra intereses de la Patria y de la Monarquía y es gravemente irreconciliable con régimen que creó esfuerzo y el sacrificio sangriento de tantos españoles, entre los que había Príncipes de Su familia unidos a El por más estrechos lazos de sangre y en cuyo Ejército El mismo tomó las armas. Programa preconiza es idéntico al de república que se proclamó tras destronar al Rey Don Alfonso XIII, su padre, y que concluyó en el incendio de las Iglesias, en la separación de las regiones, en la confusión general y en la sangrienta guerra civil ${ }^{37}$.

El traslado de Don Juan a Estoril posibilitó que Calvo Serer dedicase más tiempo a sus estudios y a ocuparse de la preparación de unas nuevas oposiciones a cátedra, esta vez de Historia de la Filosofía Española y Filosofia de la Historia de la Facultad de Filosofia y Letras de la Universidad Central. Con tal finalidad, Calvo Serer retomó su tarea investigadora con una tercera estancia en Suiza entre los meses de noviembre de 1945 y mayo de 1946, en esta ocasión financiada por el Consejo Superior de Investigaciones

34 Calvo Serer actuó como intermediario entre la censura franquista y Cardó para evitar que publicase algunas partes de su obra Histoire spirituelle des Espagnes. Etude historico-psycologique du peuple espagnol. EVL: 76/5/101. Carta de Calvo Serer a Vegas Latapié del 22 de diciembre de 1946 en la que le informa de algunas gestiones llevadas a cabo para que Cardó volviese a España y modificase algunas partes de su obra. Es interesante también la carta de Calvo Serer a Vegas Latapié del 14 de enero de 1947, EVL: 76/5/102, en la que le intentaba convencer de que el círculo del conde de Barcelona presionase a los editores para que no se publicase la obra del canónigo catalán.

35 Florentino Portero, Franco aislado: la cuestión española (1945-1950), Madrid, Aguilar, 1989, p. 61-64,

36 Manifiesto de Lausanne, en Gonzalo Redondo, Politica, cultura y sociedad en la España de Franco, 1939-1975, tomo I, La configuración del Estado español, nacional y católico (1939-1947), Pamplona, Eunsa, 1999 , p. $736-737$.

37 EVL: 76/3/135, Telegrama del 22 de marzo de 1945 que el ministro de Exteriores, José Félix de Lequerica, envió al heredero al trono. 
Científicas $^{38}$. Al volver a Madrid ganó esta cátedra de Filosofía, abandonando desde ese momento su dedicación exclusiva a la Historia, aunque su puesto requiriese conocimientos historiográficos. Desde ese momento, se adscribía a la única universidad que podía expedir títulos de doctorado, lo cual hacía especialmente importante el hecho de convertirse en catedrático de esa institución ${ }^{39}$. Sin embargo, la nueva cátedra, igual que había ocurrido con la de la Universidad de Valencia, fue sometida a reiteradas excedencias durante los cuarenta años en que Calvo Serer la ocupó.

\section{Calvo Serer: gestor cultural}

En junio de 1946, la ACNP congregó en El Escorial y Salamanca a doscientos veinticinco delegados extranjeros en el Congreso Internacional de Pax Romana, demostrando la capacidad de convocatoria de este sector católico y la posibilidad de burlar el aislamiento internacional decretado por la ONU. Ruiz-Giménez, propagandista que presidió desde muy joven asociaciones de estudiantes católicos hasta que pasó a dirigir Pax Romana en 1939, aprovechó la oportunidad y utilizó a esta organización para potenciar la imagen de los católicos españoles ante la emergente democracia cristiana europea, por lo que muchos nacionalcatólicos integristas se desvincularon de dicha organización, entre ellos Calvo Serer $^{40}$.

Al nuevo catedrático de la Universidad Central no le bastaba con la tarea docente, por lo que asumió los cargos de secretario de la revista general del CSIC, Arbor, y de la Sección de Problemas Contemporáneos de la Universidad Internacional Menéndez Pelayo. Desde estas posiciones ya podía llevar a cabo la ofensiva cultural que pretendía, encaminada a crear en España un ambiente intelectual propicio para la restauración de la monarquía. Con este objetivo, se embarcó en una nueva estancia de tres meses en el extranjero, como le hizo saber a su amigo y confidente Vegas Latapié:

[...] De donde espero mucho es de Arbor. Se están sentando las bases para hacer una cosa muy seria de Cultura Internacional, pues hay abundantes fondos de Relaciones Culturales. Me han enviado ahora con presupuesto ilimitado para la adquisición de libros y revistas. Se había llegado a una situación angustiosa por falta de material. El aislamiento que sufrimos es una cosa muy seria ${ }^{41}$.

Esta vez se desplazaba a París gracias a una beca del CSIC, cuyo objeto era el fomento de las relaciones culturales de esta institución con la intelectualidad conservadora francesa. Por esta razón, Calvo entró en contacto con el grupo de Action Française, interesándose especialmente por las obras de Charles Maurras, la pluma más célebre de

38 Oficio del Ministerio de Educación Nacional del 16 de abril de 1945 dirigido al Rectorado de la Universidad de Valencia por el que se le prorroga la licencia concedida en noviembre de 1944. AHUV: Expediente Personal: 1349/7.

39 La única tesis doctoral que dirigió fue la de Roberto Saumells, defendida en 1953 y titulada La intuición del espacio. La dialéctica del espacio.

40 En relación con la siguiente reunión de Pax Romana es interesante el telegrama enviado por RuizGiménez a Calvo Serer: "Con aprobación Jerarquía eclesiástica ruegote aceptes participar Delegación Española Veinte Congreso Pax Romana Comenzará Friburgo día 24 presente mis saludos». Al que Calvo contesta el 5 de agosto de 1946: «Agradezco invitación imposible participar Congreso. Saludos». AGUN, RCS: 1/28/361. Como se observa, Calvo Serer no aceptó la invitación por su deseo de desvincularse de esta organización católica, ya que para él, en esos momentos, el ideario de la democracia cristiana estaba muy lejos de sus convicciones.

41 EVL: 76/5/97. Carta de Calvo Serer a Vegas Latapié del 2 de diciembre de 1946. 
este grupo nacionalista francés. Mediante Armand Magescas, amigo personal de Vegas Latapié, conoció la monarquía descentralizada del teórico francés que, desde ahora, marcó sustancialmente el pensamiento del catedrático valenciano.

Un tiempo después, el ministro de Asuntos Exteriores Martín-Artajo decidió aprovechar la experiencia de Calvo en Europa y le nombró agregado cultural móvil de la Dirección General de Relaciones Culturales en febrero de 1947, momento en que el aislamiento diplomático de España era total, puesto que la Asamblea General de la ONU había condenado oficialmente al régimen franquista en diciembre del año anterior. A Calvo le fue encargada la subdirección del Instituto de España en Londres, donde permaneció un par de años. Desde allí se relacionó con parte de la intelectualidad conservadora inglesa e invitó a diversas figuras a impartir conferencias en la Universidad Internacional Menéndez Pelayo, a traducir sus obras al castellano a través de la Biblioteca de Pensamiento Actual o a colaborar en Arbor. En definitiva, allí encontró una excelente plataforma desde donde impulsar sus esfuerzos e insertarlos en los ambientes reaccionarios europeos.

Aquel verano, Calvo Serer estuvo ocupado en la gestión del curso de la Sección de Problemas Contemporáneos de la UIMP de Santander, en que participaron profesores extranjeros como Michele Federicco Sciacca, Marcel De Corte, Gustave Thibon, Alois Dempf, Christopher Hollis y españoles como Pedro Laín Entralgo, Ángel López-Amo y José $\mathrm{M}^{\mathrm{a}}$ Sánchez de Muniaín.

Al volver de Londres, en enero de 1949, Calvo Serer asumió el cargo de subdirector de Arbor, después de que Salvador Paniker hubiese abandonado el puesto. El catedrático valenciano tenía la intención de convertir a esta revista en un referente de la cultura nacionalcatólica integrista, un propósito que le enfrentó a Sánchez de Muniáin, director de la publicación que tenía otros planes para $\mathrm{Arbor}^{42}$. En última instancia el director de Arbor, un católico propagandista que había sido redactor de El Debate, subdirector de la Biblioteca de Autores Cristianos y antiguo secretario de Ángel Herrera ${ }^{43}$, fue eclipsado por Calvo Serer al consolidarse en 1948 los proyectos que el último planteaba para la revista.

Ese mismo año, Calvo Serer inauguró como director el Departamento de Culturas Modernas del CSIC, un proyecto personal que había conseguido después de reiteradas peticiones a José $\mathrm{M}^{\mathrm{a}}$ Albareda, secretario general del Consejo. Fueron meses de gran productividad para el joven catedrático, que se centró en la gestión de un grupo cultural que exponía su ideario nacionalcatólico a través de la revista Arbor, la colección Biblioteca de Pensamiento Actual que él mismo dirigía y la Sección de Problemas Contemporáneos de la UIMP.

Para llevar a cabo sus planes culturales, Calvo Serer se rodeó de un equipo de universitarios que emprendió una renovación del conservadurismo tradicional y monárquico siguiendo la línea iniciada por Acción Española en los años treinta. Estaban convencidos de que se encontraban en el momento idóneo para continuar esta tarea puesto que en 1948 se celebraba el cincuentenario del Desastre de 1898, el centenario de las revoluciones europeas de 1848 y el tricentenario de la firma de los Tratados de Westfalia. Como reivindicaban que aquel era el momento ideal para repensar la esencia de España, Jaime Vicens Vives los bautizó como «generación de $1948 »^{44}$.

42 José Marti Gómez y Josep Ramoneda, op. cit., p. 21-22.

43 Para una aproximación biográfica a este personaje, consúltese Jesús TANco LerGA, «José Maria Sánchez de Muniaín y Gil de Vidaurre», Debate actual: revista de religión y vida pública, 13 (2009), p. 109-118. Jaime Vicens VIves, «La España del siglo XVII», Destino, núm. 616, 1949. 
El hecho de que Vicens Vives hubiese dado nombre al grupo de Calvo Serer y que al último le hubiese caído en gracia tal denominación, ya que hacía tiempo que buscaba un apelativo para su grupo, hizo que se estrecharan las relaciones entre ambos. A partir de la publicación del artículo de Vicens, el catalán participó asiduamente en los cursos, conferencias y publicaciones de Calvo Serer y Pérez Embid. Sus obras eran publicitadas en Arbor, algunos de sus discípulos fueron becados o premiados por el CSIC y el Centro de Estudios Históricos Internacionales que dirigía Vicens fue incluido en el Patronato «Saavedra Fajardo» del Consejo, del que Calvo era secretario ${ }^{45}$. Recíprocamente, Vicens invitaba a Calvo Serer y Pérez Embid a participar en las conferencias que organizaba en Barcelona y en los Anuarios que pretendía publicar ${ }^{46}$. Sin embargo, esto no ha de conducir a concluir que Vicens Vives formase parte del grupo político-cultural que Calvo Serer encabezaba.

En el verano de ese año, Calvo Serer quiso plasmar por escrito sus reflexiones sobre el momento cultural que vivía España y sobre su propia actividad e intenciones en un detallado «Informe sobre el desarrollo posible de una acción cultural», en que exponía la necesidad del dominio de plataformas culturales a través de las cuales poder influir en la política del régimen ${ }^{47}$. Su plan de acción se estaba materializando mediante el control de la revista cultural Arbor, de la editorial Rialp, del Ateneo de Madrid y de los Departamentos de Culturas Modernas y de Filosofía de la Cultura del CSIC.

Unos meses después, Calvo Serer publicaba en la Biblioteca de Pensamiento Actual una recopilación de sus artículos escritos últimamente alrededor de la idea de España bajo el título España, sin problema. Con esta obra consiguió el Premio Nacional de Literatura y un enorme éxito por la defensa enconada de una nación tradicional, monárquica, católica, descentralizada y europeísta.

En junio de 1951, Calvo Serer se convirtió en el director de Arbor y tomó definitivamente las riendas de la revista. Desde ese momento aumentaron considerablemente los trabajos humanísticos en detrimento de los cientificos, puesto que Calvo y sus hombres entendían

45 Juan Mercader Riba obtuvo el Premio «Menéndez Pelayo» del CSIC en 1946 por el libro fruto de su tesis doctoral Barcelona durante la ocupación francesa y fue becario del Instituto «Jerónimo Zurita» entre 1945 y 1950. A pesar de que Vicens no fue su director de tesis, era uno de sus más cercanos colaboradores. Cambió su status a colaborador científico, contratado junto a Joan Reglà, de la Sección de Barcelona del Instituto «Jerónimo de Zurita» desde 1952 hasta 1954. Por su parte, Joan Reglả también obtuvo el Premio «Menéndez Pelayo» del CSIC en 1948 por su tesis doctoral publicada como Francia, la Corona de Aragón y la frontera pirenaica. La lucha por el valle de Arán (siglos XII-XIV). Fue becario de la Sección de Barcelona del Instituto «Jerónimo de Zurita» desde 1949 hasta que fue contratado como colaborador cientifico.

46 Carta de Vicens Vives a Calvo Serer del 22 de diciembre de 1949 en que, entre otras cuestiones, le comenta algunos aspectos sobre las conferencias La formación histórica de la Europa actual: «[...] He incluido en el programa vuestros nombres, el de Pérez Embid y el tuyo [...]. Los temas serian "Federalismo y centralismo en la historia contemporánea" -el de Embid- y "La crisis del siglo XX y la filosofia católica española" -el tuyo-. Hazme el favor de contestar rápidamente si os gustan fecha y tema. [...] No sé qué decir ni qué me tachará el censor; pero desde luego llamaré la atención sobre el libro [España, sin problema] al público. Más adelante, en cuanto nos veamos, podremos discutir tus principales tesis». AGUN, RCS: 1/32/571.

En una carta posterior, Calvo anunciaba a Vicens que Pérez Embid iba a hablar en el Ateneo de Madrid sobre «El problema de España en el pensamiento español contemporáneo» y él sobre «La guerra española (1936-1939) en la Literatura universal». Además, le comentaba: «[...] me gusta el tema que me propones. Pero esta vez quizá fuera más eficaz la del Ateneo con variantes, dada a los dos días en Barcelonay. Es llamativo que no acepten las propuestas de títulos de Vicens, que eran mucho más atrevidas. AGUN, RCS: 1/32/618, Carta de Calvo Serer a Vicens Vives del 31 de diciembre de 1949.

47 AGUN, RCS: 1/61/4. Informe del 15 de julio de 1949. 
la publicación como una plataforma desde la cual exponer sus ideas sobre el presente y el pasado de la nación española. Sin embargo, el secretario general del CSIC, José Ma Albareda, se resistía a que Arbor abandonara su cariz científico y despolitizado y dejara de ser la revista general del Consejo $0^{48}$.

En este orden de acontecimientos, Florentino Pérez Embid, el colaborador más cercano a Calvo en ese momento, alcanzó la Dirección General de Propaganda del nuevo Ministerio de Información y Turismo, en manos de Gabriel Arias Salgado. Este cargo, que en 1952 tomó el nombre de Dirección General de Información, tenía las competencias de Publicaciones Españolas y del Ateneo de Madrid, por lo que desde aquí podía influir notablemente en la política cultural del país y favorecer la difusión del ideario del grupo cultural al que pertenecía.

Ese mismo año, Calvo Serer entró a formar parte del consejo privado del conde de Barcelona y publicó su obra en defensa del restablecimiento de la tradición Teoría de la Restauración. También entonces empezó una mayor vindicación del regionalismo, punto intermedio, según Calvo, entre el centralismo y el separatismo. A través de artículos en el periódico monárquico $A B C$, en Las Provincias y en Arbor defendió la España de la periferia y un tipo de nación donde todas las regiones pudiesen contribuir a la grandeza nacional, mensaje que en los años treinta había defendido Acción Española. El grupo de Calvo Serer revitalizaba esa idea de España en un contexto en que no sólo estaban en juego diferentes sensibilidades de carácter cultural, sino que también se enfrentaban dos maneras de entender el franquismo.

Unos meses después, Calvo Serer consiguió que le permitieran publicar su polémico libro La configuración del futuro, una recopilación de algunos de sus últimos artículos publicados en España o en el extranjero que no en balde dedicaba a Antonio Rodilla y al Colegio del Beato Juan de Ribera de Burjassot, reconociendo de este modo el magisterio y la influencia del rector del colegio en la conformación de su pensamiento.

Continuó con sus reivindicaciones y en septiembre de 1953 publicó el artículo «La politique intérieure dans l'Espagne de Franco"' en la revista reaccionaria francesa Écrits de Paris. En este texto ponía de manifiesto la existencia de marcadas diferencias entre los actores culturales del régimen y criticaba la política del ministro de Educación RuizGiménez ${ }^{49}$. Patentizaba la convivencia de distintas familias políticas y reclamaba que Falange y la ACNP diesen paso a una «tercera fuerza» que él mismo encabezaba. Incluso revelaba las identidades de los componentes y el programa de la «tercera fuerza», que abogaba, entre otras cuestiones, por la descentralización administrativa del Estado.

En los días siguientes el artículo circuló profusamente en su versión francesa o traducida al castellano, gracias a la difusión que el mismo autor hizo al enviarla a amigos y conocidos, e incluso a los ministros de Información y Turismo y de la Presidencia, que habían mantenido hasta entonces estrechas relaciones con Calvo Serer. Pero Franco no soportó que un catedrático criticara en una revista extranjera la política de uno de sus ministerios en el preciso momento en que España acababa de firmar el Concordado con el Vaticano y los acuerdos con los Estados Unidos. El atrevimiento de Calvo fue intentar desmentir en el extranjero el apoliticismo del régimen y por eso Franco ordenó que se cerrasen las filas.

48 AGUN, RCS: 1/39/497. Carta de Calvo Serer y Pérez Embid dirigida a Albareda del 12 de diciembre de 1951 en que se quejan por no haber recibido las subvenciones acordadas y piden fondos para llevar a cabo sus planes.

49 Rafael Calvo Serer, «La politique intérieure dans l'Espagne de Franco», Écrits de Paris, núm. 107, 1953, p. 9-18. 
Así, el 14 de octubre de 1953 Calvo Serer fue destituido de todos los cargos que ocupaba en el CSIC, es decir, como director del Departamento de Culturas Modernas y de la revista Arbor, vocal de la Junta del Patronato «Raimundo Lulio» y de la Comisión Permanente de los Patronatos «Raimundo Lulio», «Marcelino Menéndez Pelayo» y «Saavedra Fajardo» ${ }^{50}$. Sin embargo, no fue sancionado como catedrático de la Universidad Central, a pesar de haber recibido ásperas críticas de su alumnado y del claustro de profesores, causa por la cual pidió una excedencia para ir a Londres a investigar hasta que la situación se apaciguara.

\section{Un monárquico convencido}

Calvo Serer empezó una nueva etapa de estancias en el extranjero en que fue a Londres, Bonn y Roma, donde pudo comprobar cómo habían cambiado las cosas en Europa en una década. Durante los primeros meses de 1954 estableció su base de operaciones en la capital inglesa y, al volver a Madrid, pidió audiencia a Franco para explicarle las motivaciones que lo habían empujado a publicar el artículo en Écrits de Paris. Cómo no obtuvo respuesta, le envió una larga carta en que se quejaba de las agresiones que había sufrido y donde le explicaba que si publicaba en el extranjero era porque la censura no se lo permitía en España. Asimismo, se quejaba de la inclusión del pensamiento de izquierdas en el Movimiento Nacional y de la difamación que habían sufrido las ideas tradicionalistas ${ }^{51}$. A pesar de las continuas negativas, perseveró en el intento de conseguir una entrevista con Franco, audiencia que llegó finalmente en diciembre de 1955.

Ese año publicó en la Biblioteca de Pensamiento Actual, que todavía dirigía, Política de Integración, en que insistió, una vez más, en el análisis de los conflictos culturales que habían tenido lugar hasta ese momento en la España de Franco, a pesar de que el régimen se preocupase por desmentirlas. De hecho, con el objetivo de continuar la pugna por que el nacionalcatolicismo integrista dominase el espacio público, Calvo Serer y otros monárquicos formaron, unos meses más tarde, la Asociación «Amigos de Maeztu». Como presidente nombraron al conde de Ruiseñada, como vicepresidentes a Pemán y Arauz de Robles y ocuparon el cargo de vocales Calvo Serer, Valdeiglesias, Jorge Vigón, Juan Ignacio Luca de Tena, Fernández de Mora, Vegas Latapié, Millán Puelles, Martín Almagro y el marqués de la Eliseda. Durante unos años se encargaron de organizar varios actos en defensa de la actualización del pensamiento de Maeztu, que implicaba la reivindicación de los valores nacionalcatólicos, pero no disfrutaron de demasiado $\mathrm{eco}^{52}$.

Los célebres disturbios universitarios de febrero de 1956, que provocaron la caída del ministro de Educación Ruiz-Giménez y del ministro-secretario general del Movimiento Fernández-Cuesta, tuvieron como consecuencia un cambio de gobierno en que entraron una serie de personas que habían estado relacionadas, de una u otra forma, con Calvo Serer como eran Jorge Vigón, Jesús Rubio, Mariano Navarro Rubio, Joaquín Planell, Alberto Ullastres o Laureano López Rodó. Simultáneamente, algunos hombres del nacionalcatolicismo integrista entraban en el Consejo Privado del pretendiente al trono,

50 AGUN, RCS: 1/46/139. Oficio del CSIC del 14 de octubre de 1953.

51 AGUN, RCS: 1/58/376. Carta de Rafael Calvo Serer a Francisco Franco del 16 de diciembre de 1954.

52 Pablo Hispán Iglesias de Ussel, La politica en el régimen de Franco entre 1957-1969. Proyectos, conflictos y luchas por el poder, Madrid, Centro de Estudios Politicos y Constitucionales, 2006, p. 50. 
como Pérez Embid o Gonzalo Fernández de la Mora, en un último intento de acercamiento de las posiciones de Franco y Don Juan ${ }^{53}$.

Poco tiempo después, Calvo Serer publicaba La fuerza creadora de la libertad que, una vez más, recogía una serie de trabajos aparecidos anteriormente en prensa, en este caso entre 1953 y 1957. En esta obra se ponía de manifiesto el cambio ideológico experimentado por Calvo Serer a raíz de su salida de España. Su título ya evidenciaba la valorización que hacía de la libertad, un concepto rechazado hasta entonces en su ideario, reivindicando «la democracia representativa -que no implica necesariamente ni partidos ni sufragio universal- -1$\rangle^{54}$, es decir, abogando por la monarquía tradicional y por la restauración de la universitas cristiana.

Meses más tarde, en mayo de 1958, el Departamento de Estado norteamericano invitó al catedrático valenciano para que conociera el sistema político de los Estados Unidos, pero la estancia se prolongó más de lo previsto por una intervención quirúrgica de urgencia que le fue practicada debido a una complicación en la vesícula ${ }^{55}$. Esto le permitió analizar más a fondo el contexto norteamericano, un conocimiento que puso de manifiesto en obras posteriores, mostrándose cada vez más interesado por el mundo anglosajón.

Dos años más tarde, plasmó sus impresiones sobre la sociedad americana en una conferencia impartida en el Ateneo Mercantil de Valencia, que fue posteriormente publicada como Nuevas formas de democracia y libertad. Este ensayo fue duramente criticado por Vegas Latapié, dado que en él Calvo reconocía que las democracias habían dado lugar a éxitos económicos y sociales. Sin embargo, defendía que en España se había de establecer una monarquía tradicional como vía intermedia entre el liberalismo y el marxismo, un modelo que, para Calvo, tenía que ser lo más similar posible a la democracia norteamericana ${ }^{56}$.

A principios de 1962 pudo llevar a cabo una nueva visita a Washington para seguir indagando en el funcionamiento del sistema político y económico norteamericano, que lo había fascinado, gracias a otra excedencia de su cátedra en la Universidad Central. Unos meses más tarde publicó en la Editora Nacional La literatura universal sobre la guerra de España, un ensayo de setenta y cuatro páginas que no tuvo gran trascendencia, aunque, como había hecho antaño, envió a amigos y allegados ${ }^{57}$. Y dos años después, en 1964, vio la luz Las nuevas democracias, que ocupaba el volumen ciento veinticinco de la Biblioteca de Pensamiento Actual y recogía numerosos trabajos publicados en periódicos españoles o extranjeros. Insistía en que el futuro español era la monarquía tradicional combinada con el ejercicio de las libertades de expresión, asociación y representación política, al tiempo que defendía la compatibilidad entre autoridad y libertad, tal y como se daba en México y Turquía.

Desde ese año, Calvo Serer empezó a intervenir de manera más activa y directa en los proyectos del diario Madrid y en el verano de 1966 fue nombrado presidente de su Consejo de Administración. Esto fue posible gracias a la propuesta de Luis Valls Taberner, que sabía que su amigo valenciano pretendía influir en la opinión pública a través de esta plataforma de acción cultural. Así, después de unos años de relativo ostracismo, Calvo Serer volvía a

53 Pérez Embid entró en el Consejo Privado de Don Juan en 1957, mientras que Fernández de la Mora lo hizo en 1959

54 Rafael Calvo Serer, La fuerza creadora de la libertad, Madrid, Rialp, 1958, p. 356.

55 Rafael Calvo Serer, Mis enfrentamientos..., op. cit., p. 19.

56 Rafael Calvo Serer, Nuevas formas de democracia y libertad, Madrid, Ateneo, 1960, p. 37.

57 Rafael CALVO SERER, La literatura universal sobre la guerra de España, Madrid, Editora Nacional, 1962. 
la palestra y despertaba, al menos, la expectación de la opinión pública. Desde septiembre de 1967, el catedrático valenciano aumentó el control que tenía sobre el Madrid al nombrar como director del periódico, en sustitución de Miner Otamendi, a Antonio Fontán, un estrecho colaborador suyo en aquel momento. La relación con el antiguo director se había enrarecido y en marzo del mismo año se negó a publicar un editorial de Calvo en que criticaba la Ley de Representación Familiar en Cortes. Fue entonces cuando el presidente del Consejo de Administración del Madrid decidió el cambio de dirección.

La página tercera se convirtió en el lugar en que Calvo Serer y otras plumas afines expusieron sus opiniones sobre la política, la cultura, la economía y la sociedad del momento. Aun así, no había en el periódico una ideología uniforme, sino más bien una actitud común favorable al pluralismo político, la reforma del régimen y la modernización del país. Este diario había sido uno de los pocos que había obtenido una licencia de apertura después de la Guerra Civil, puesto que quien era su director en aquel momento, Juan Pujol, era de probado carácter conservador. Pero desde los años sesenta el Madrid se había erigido en una de las tribunas públicas que reclamaban, aunque tímida y sutilmente, la evolución del régimen, la democratización de la sociedad y el reconocimiento de los derechos individuales y de las libertades, fundamentalmente de la libertad de información. Estas peticiones se llevaban a cabo en artículos y editoriales, algunos de ellos escritos por Calvo Serer, que aprovechando la Ley de Prensa de Manuel Fraga de 1966, reivindicaban una mayor participación de la ciudadanía en el sistema político.

De hecho, en 1968 el catedrático valenciano recopiló ochenta de estos artículos que se habían publicado durante los dos años anteriores en el volumen España ante la libertad, la democracia y el progreso. En estos artículos abogaba abiertamente por una transición democratizante que posibilitase la incardinación definitiva de España en la Europa del Mercado Común. Pero aquel verano, Calvo fue más lejos y publicó en la página tercera del Madrid, utilizando como mal disimulado pretexto la situación de Francia después de mayo del 68, «Retirarse a tiempo. No al General De Gaulle», que se podía leer como una invitación a la retirada de Franco. Como consecuencia de la publicación de este artículo se cerró el periódico durante dos meses y se le impuso una multa de doscientas mil pesetas.

Un tiempo después, Calvo Serer decidió volver a atacar y, como en 1953, publicó un artículo en Francia, en este caso en Le Monde, en que reivindicaba la existencia en España de una cuarta fuerza reformadora que tenía que asumir la dirección del país después de la implantación de las libertades de expresión y asociación. Aun así, como también había hecho años atrás, antes de la publicación dirigió una larga misiva a Franco donde explicaba su visión de la política del régimen ${ }^{58}$.

De este modo, el 11 de noviembre de 1971, veía la luz «Moi, aussi j'accuse...», en que se formulaban graves críticas a algunos miembros del gobierno, entre los cuales estaba Carrero Blanco. El artículo circuló en España y, en seguida, el Tribunal de Orden Público abrió proceso a Calvo. Sin embargo, como había decidido quedarse en París hasta que las reacciones al artículo se apaciguasen, se le declaró en rebeldía. En la capital francesa se dedicó a preparar la edición de algunas obras como Franco frente al Rey y La dictadura de los franquistas, o a publicar algunos artículos de opinión en la prensa diaria.

El 25 de noviembre de 1971 se había cerrado el diario Madrid por irregularidades administrativas y meses después de su clausura se llevó a cabo la voladura del edificio

58 Carlos Barrera, El diario Madrid. Realidad y simbolo de una época, Pamplona, Eunsa, 1995, p. 484 y ss. 
que había sido su sede. La prensa tomó esta acción como símbolo de la aniquilación de una de las voces que en los últimos años se había opuesto a algunas de las decisiones gubernamentales $^{59}$. Con el exilio y la clausura del Madrid acabó la última de las iniciativas culturales instigadas por Calvo Serer, desde donde había contribuido a la definición de la naturaleza de España en un momento en que volvía a ser tema de debate y, tanto entonces como antes, defendió que España tenía que ser monárquica y regional.

Desde París contribuyó al nacimiento de la Junta Democrática de España junto a Santiago Carrillo, que fue presentada por ambos en julio de 1974 y cuyo objetivo era la reivindicación de la evolución hacia un sistema político democrático. Durante los siguientes meses Calvo Serer viajó por numerosos países de Europa, América y África como delegado exterior de la misma, que en marzo de 1976 se unió a la Plataforma de Convergencia Democrática para dar lugar a la Platajunta. Después de este periplo, de la muerte de Franco y de casi cinco años de exilio decidió que era el momento de volver a España y así lo hizo en junio de 1976.

Al llegar al aeropuerto de Barajas fue detenido e informado de que la Fiscalía le buscaba desde 1972. Permaneció en la prisión de Carabanchel durante dos semanas y posteriormente fue puesto en libertad condicional. La aplicación a su caso del indulto otorgado por Juan Carlos I en noviembre de 1975 supuso su plena libertad. La estancia en la prisión en que habían residido la mayoría de los presos políticos del franquismo fue recordada desde ese momento en numerosas ocasiones por el catedrático valenciano, especialmente en su obra Mis enfrentamientos con el poder, puesto que, según su opinión, esto contribuía a reforzar su pedigrí de demócrata.

Con posterioridad a este episodio se retiró de la vida política, aunque siguió escribiendo artículos y pronunciando conferencias en diferentes instituciones. Aún iba a publicar en febrero de 1979 La solución presidencialista, que recogía artículos escritos entre 1972 y 1974. En alguno de ellos exponía los objetivos de la Junta Democrática: «restablecimiento inmediato de las libertades públicas, preparación de un gobierno de transición en el que estuvieran representadas todas las fuerzas democráticas y celebración de una consulta popular sobre la forma definitiva del Estado». Su último libro apareció en 1982 y se tituló Eurocomunismo, Presidencialismo y Cristianismo, tratándose una vez más de un compendio de artículos que había ido publicando desde 1980.

Finalmente, Rafael Calvo Serer murió en la Clínica Universitaria de Pamplona, el 19 de abril de 1988, como consecuencia de un cáncer de colón a los setenta y un años de edad. Desaparecía un intelectual católico, conservador y monárquico que había luchado durante toda su vida por que su idea de España prevaleciese en el panorama cultural del franquismo.

59 Ibid., p. 534 y ss. 